\title{
When the sum of the parts is greater than the whole
}

Virginia R. Litle, MD

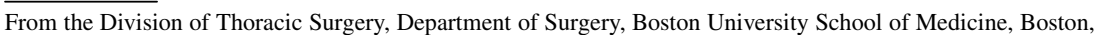
Mass.

Disclosures: Author has nothing to disclose with regard to commercial support.

Received for publication June 22, 2016; accepted for publication June 22, 2016; available ahead of print July 16, 2016.

Address for reprints: Virginia R. Litle, MD, Division of Thoracic Surgery, Department of Surgery, Boston University, 88 E Newton St, Robinson B402, Boston, MA 02118 (E-mail: Virginia.litle@bmc.org).

J Thorac Cardiovasc Surg 2016;152:754-5

0022-5223/\$36.00

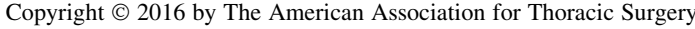

http://dx.doi.org/10.1016/j.jtcvs.2016.06.041

Limited pulmonary resection serves several purposes: to optimize long-term pulmonary function, to allow patients at higher risk to benefit from surgical resection, and to allow patients at standard risk to benefit from future surgical resections of metachronous primary tumors. With regard to longterm pulmonary function, more than 25 years ago the Lung Cancer Study Group concluded that there were no significant differences in late pulmonary function after lobectomy versus limited resection. ${ }^{1}$ The wall was then built - albeit brieflyfor advances in parenchymal-sparing surgery for early lung cancer. Although pulmonary function is important, the primary concern has always been that of oncologic compromise. In the past 2 decades, we have seen the thoracic surgical innovators and fans of the sublobar resection forge ahead and demonstrate that lesser resection does not necessarily reduce cancer-related survival in patients with early stage disease. Aside from survival, however, quality-of-life and parenchymal preservation are possible and may have a long-term "functional benefit." 4 A lung-sparing approach is no longer just a trend, and Asian and North American clinical trials are open. ${ }^{5,6}$ Accuracy in reporting long-term functional status and precise definition of what constitutes a segmentectomy are therefore important.

In this issue of the Journal, Nomori and colleagues 7 demonstrate that not all segmentectomies are equivalent. Specifically, with regard to the extent of lung resection, the left upper division (LUD) segmentectomy (also known as the lingular-sparing trisegmentectomy) should not be placed in the general segmentectomy basket. ${ }^{7}$ Why not? When Nomori and colleagues ${ }^{7}$ looked at regional lung perfusion with single-photon emission computed tomography and measured pulmonary function tests, they found that the LUD segmentectomy was equivalent to a left upper lobectomy with regard to what they deemed lobar and systemic function. They theorized that the remaining lingula did not pull its weight after being spared and that, not surprisingly, resection of the large LUD or trisegments functionally spares little parenchyma.

This article contributes to the literature because there are no previous comparisons of pulmonary function tests and lung perfusion after segmentectomies. The results thus

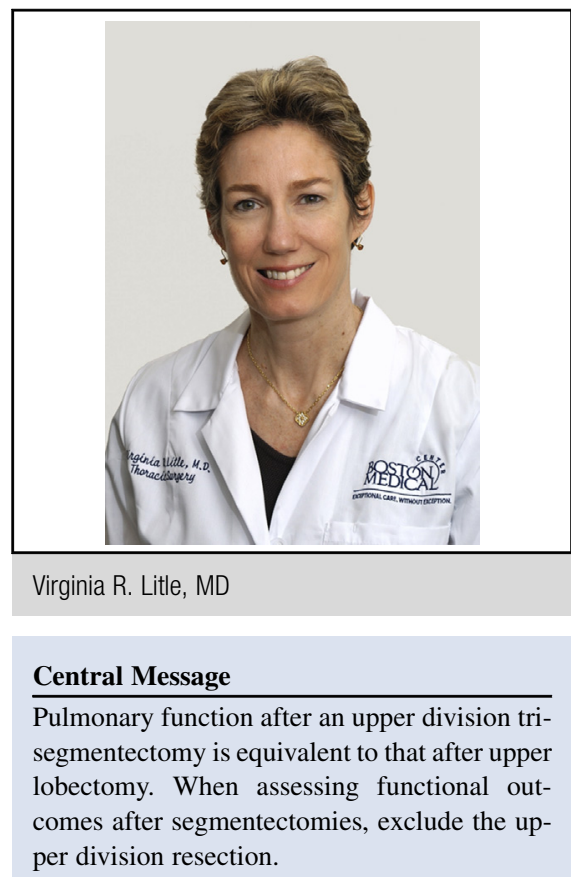

See Article page 747. will have research and clinical utility. This finding will be important for designing new clinical trials of sublobar resections and for analyzing the results of the current ones including Cancer and Leukemia Group B 140503 and Japan Clinical Oncology Group 0802/West Japan Oncology Group 4607L, in which pulmonary function is also a clinical end point. ${ }^{8}$ In addition, as the segmentectomy become an established option in the algorithm for deciding extent of resection of ground glass opacities, ${ }^{9}$ the results of Nomori and colleagues ${ }^{7}$ would support relegating the LUD to the left upper lobe category. It has been shown, first by Macke and associates ${ }^{4}$ and now by Nomori and colleagues, ${ }^{7}$ that a segmentectomy is not a segment by any other name, and we should use categories of segments resected (1-2, 3-5) when reporting and making clinical decisions. For the case of the LUD, with its 3 segments, the article of Nomori and colleagues $^{7}$ shows that resection of the LUD does not play by the rules and probably should not be classified into either of these segmentectomy categories. In this case, the sum of the 3 segments equals 5 .

\section{References}

1. Ginsberg RJ, Rubinstein LV. Randomized trial of lobectomy versus limited resection for T1 N0 non-small cell lung cancer. Lung Cancer Study Group. Ann Thorac Surg. 1995;60:615-22; discussion 622-3. 
2. Keenan RJ, Landreneau RJ, Maley RH Jr, Singh D, Macherey R, Bartley S, et al. Segmental resection spares pulmonary function in patients with stage I lung cancer. Ann Thorac Surg. 2004;78:228-33; discussion 233.

3. Kodama K, Doi O, Higashiyama M, Yokouchi H. Intentional limited resection for selected patients with T1 N0 M0 non-small-cell lung cancer: a single-institution study. J Thorac Cardiovasc Surg. 1997;114:347-53.

4. Macke RA, Schuchert MJ, Odell DD, Wilson DO, Luketich JD, Landreneau RJ. Parenchymal preserving anatomic resections result in less pulmonary function loss in patients with stage I non-small cell lung cancer. J Cardiothorac Surg. 2015; 10:49.

5. Landreneau RJ, Normolle DP, Christie NA, Awais O, Wizorek JJ, Abbas G, et al. Recurrence and survival outcomes after anatomic segmentectomy versus lobectomy for clinical stage I non-small-cell lung cancer: a propensity-matched analysis. J Clin Oncol. 2014;32:2449-55.
6. Okada M, Mimae T, Tsutani Y, Nakayama H, Okumura S, Yoshimura M, et al Segmentectomy versus lobectomy for clinical stage IA lung adenocarcinoma. Ann Cardiothorac Surg. 2014;3:153-9.

7. Nomori H, Cong Y, Sugimura H. Systemic and regional pulmonary function after segmentectomy. J Thorac Cardiovasc Surg. 2016;152:747-53.

8. Kent MS, Mandrekar SJ, Landreneau R, Nichols F, DiPetrillo TA, Meyers B, et al Impact of sublobar resection on pulmonary function: long-term results from American College of Surgeons Oncology Group Z4032 (Alliance). Ann Thorac Surg. 2016;102:230-8.

9. Kodama K, Higashiyama M, Okami J, Tokunaga T, Imamura F Nakayama T, et al. Oncologic outcomes of segmentectomy versus lobectomy for clinical T1a N0 M0 non-small cell lung cancer. Ann Thorac Surg. 2016; 101:504-11. 